\title{
PLANNING FOR DISASTER
}

\author{
W. C. Hodge
}

\begin{abstract}
SUMMARY
The Author relates the post event activities and the successful reconstruction work at the Bay of Plenty Mill operated by Tasman Pulp and Paper Company Limited following the 1987 Edgecumbe Earthquake. The paper outlines suggestions, based on actual experience, which may be used as a guide in Planning for Disaster.
\end{abstract}

\section{INTRODUCTION}

The 1987 earthquake resulted in a traumatic situation whereby we had to make a sudden adjustment from managing a production facility to managing the re-establishment of that facility because of the damage incurred. The fact that we made a speedy recovery can be attributed to the fact that people were immediately re-organised to give the best spread of skills to tackle the new objectives posed by the disaster together with the timely development of a strategy to achieve a satisfactory level of results.

Some of the actions we took are worth expounding from the point of view that many of the decisions could have been made beforehand and it may well be of benefit to others to initiate such planning now.

\section{EVENT RECOVERY}

In the 1987 situation our reactions evolved spontaneously as a matter of necessity but were quickly converted into specifics as the initial impact wore off and fear was replaced by more objective analysis of the situation. The primary objectives were to save lives, minimise injuries, carry out early inspections, record modes of failure, make areas safe and arrive at rapid decisions on repairs, restore normal operating conditions quickly, effect total repairs and settle all insurance claims expeditiously.

It is worth noting that in the immediate

* Engineering Manager

Tasman Pulp and Paper co. Ltd, Kawerau post event situation we found there was no power, no water, no communications, no domestic or process sewer services available and from the nature of the plant we could have been faced with a significant fire or hazardous chemicals spill.

obviously the first concern was the safe evacuation of personnel from the premises with a check on numbers to ensure that no one was missing. Following medical treatment, the evacuation of the injured from the immediate area was hampered by the closure of many roads. The arrival of the Army with the Air Force helicopters was a welcome sight given the sudden isolation following the earthquake.

The organisation within the company to deal with the emergency fell into place on two fronts simultaneously, in security and in Engineering.

The mill security group are trained in first aid, the use of breathing apparatus and are equipped to fight fires. The Company tests the alarms for gathering at emergency shelters each week and from time to time full scale evacuations are carried out.

This procedure no doubt contributed to the orderly evacuation. It may be of some interest to note that of the twelve hundred or so people on the site at the time of the main shock there were only three injuries.

While the place was still shaking a firm of Engineers in Auckland was contacted to put together a group of structural experts to assist with inspections and design of repairs. Plans were made to bring them in by charter aircraft. contact with the outside world was erratic as telephone Iines were only available for short spells on an infrequent basis and we were lucky to make the arrangements as quickly as we did. 
The airstrip had to be checked to ensure that a plane could land and as soon as these Engineers from Auckland arrived they were combined with mill engineers, operators and maintenance personnel to form inspection groups to give a $\mathrm{mix}$ of local knowledge and independent expertise. It should be remembered that most of the local people were subject to problems at their homes and were in a state of shock. That so many made themselves available for inspection work is testimony to the dedication of these individuals.

It may not be well known but many people left the area and didn't come back. Many who left for a short time and came back seem to be in a state of acute sensitivity to any vibration, however normal.

Those of us who worked through the whole exercise already have our emergency kits packed and our cars filled.

A separate temporary project office was established as a control centre through which all site activities were directed and where all meetings were held during the first few days after the emergency.

One impact that was readily identifiable was the immediate need for a wide range of construction goods and we implemented a crash procurement programme to buy in construction materials and plant from nearest sources. Items such as structural steel, concrete blocks, lumber, scaffolding, tarpaulins, cladding materials, water piping, pressure piping, valves, portable air compressors, generators, welding and cutting equipment, transportable cranes, etc..

A primary objective was to determine the extent of the damage and likely outage time and to set up regular and frequent meetings with the insurance assessors. Once we determined the likely loss of production our marketing people were faced with finding substitute product for our customers. Even with insurance it is still necessary to retain customers.

We decided to implement a data base recording system to $10 \mathrm{~g}$ all damage reports, minutes of meetings, photographs and correspondence and make these available to the assessors. This is classified in construction jargon as "warts and all". This means that the assessors could monitor all of our actions all the time whether this showed us in a poor light or not. No one can do everything right all of the time.

We set up a computer planning system networked on desk top computers on which each Area Engineer was responsible for planning all work in his area. All of the schedules were interfaced to give an overall picture which was of immense value in controlling the work and in reassuring the assessors and insurers that the repairs were being handled in an expeditious, professional manner.

It was necessary to design temporary emergency works based on available material for safety items such as props for sagging structures, repairs to fire mains etc. Many areas had to be made safe for access and those not readily fixed had to be identified in order to limit entry.

We had to make a decision on the degree of repair or rebuild and set design and construction standards. This was particularly important with structures built in different time windows to differing code details. To a lesser degree this was impacted by the terms of the policy: It was necessary to obtain Local Authority approval for the repair standards. There was no question of making all structural repairs to NZS 4203 because of the wide range of ages in the plant structures. We adopted a policy to replace damaged plant to the same level as before and to repair older buildings to some level towards NZS 4203, much along the lines adopted by Wellington City Council in their programme of strengthening old city buildings [1]. However we did incorporate some minor detail changes that cost no more and improved the earthquake performance of a particular part.

In order to open up as many work fronts as possible we had design being carried out on temporary repairs as well as on permanent repairs at the same time.

We found it advantageous to categorise damage into work which must be done for safety, to restore services, to restore maintenance facilities and to start up the plant. We set three priority levels as follows :-

Prlority 1 - Work necessary to give safe access to buildings and process areas. Generally the work consisted of temporary props, cable ties, anchors, demolition of any dangerous structures too badly damaged to save and included the removal of all loose masonry and debris.

Priority 2 - Work necessary to allow the plant to be serviced and brought back into operation. This consisted of replacing bent and broken bracing, repairs to concrete cover which spalled, with particular emphasis on columns and shear walls and included all machinery inspections and repairs.

Priority 3 - work necessary for the long termwell being of the plant but which could be done safely during normal production operations.

It was necessary to decide the best use of direct production labour while the plant was shut down. Those with trade skills went to reconstruction teams or clean-up gangs and others went to assist in the community.

With a wide range of major specialised equipment, the services of major vendor personnel was essential to verify detail damage to specialty plant and to help with the procurement of machine pads. From the second day on we had representatives from major vendors arriving from all over the world to assist with the work. 
Without describing the process in detail, which is described in reference 2 , we established that from the two/three stream process we could pick one path going from line to line which could give an early restart to some production.

It is worth bearing in mind that in many areas, even in modern design, cover concrete fell off, sometimes from a great height and in sizeable pieces, posing a hazard to personnel escaping from the buildings. Office escape routes were cut off in some cases by filing cabinets and bookshelves which went walkabout during the violent shaking before falling over and seemingly piling up. In some cases there were a few narrow escapes for office staff. A similar situation was found to exist in the stores area where goods fell off the shelves and some of the shelves collapsed or fell over.

one of the sobering conclusions we reached on inspecting the damage was that had the felt intensity been marginally greater or the shaking of longer duration then all the buildings would have been down. The design philosophy in New Zealand, based on the response spectra of the 1940 El Centro earthquake, allows for structural deformation to dissipate the earthquake energy. We had a situation which closely resembled that at $E I$ centro, hence it can be said that we experienced a design earthquake. The foregoing design philosophy is fine but can lead to a false sense of security in any cases where the duration or felt intensities are greater than the design earthquake. People may in fact stay indoors too long!

\section{ORGANISATION}

It is important to create an organisational structure which can deal with the emergency and its aftermath. The organisation to run an efficient production operation is not necessarily the one to achieve the best results in a disaster recovery programme. Flexibility within the management structure is a key element for an acceptable result.

Figure 1 shows the basic mill structure, other functional disciplines have been ommitted for the sake of clarity. To stress the flexibility and changed objectives the titles above are not those used in our organisation. The ones used here more clearly identify the roles involved.

Figure 2 shows the importance we placed on organising to deal with the insurance claim. We took the view that there could be a need to have additional advice available from specialist advisors. These advisors were informal and always remained in the background although the assessors were aware that they existed. Our relationships with all the parties involved were such that the valuable advice from such sources were used in a low key mode.

Figure 3 illustrates the arrangement during the first week with a very flat organisation to carry out inspections and report their findings. This was a week of intense activity and decision making, not

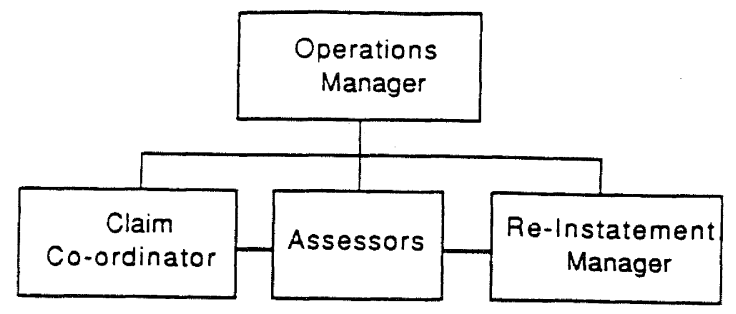

FIGURE

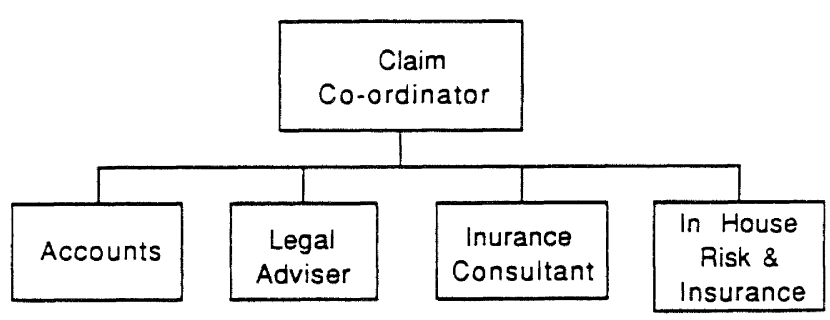

FIGURE 2

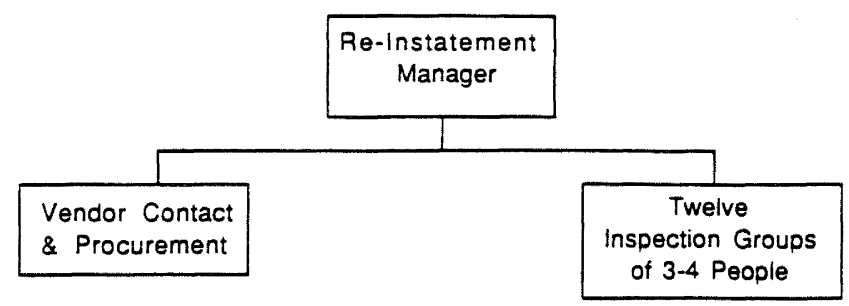

FIGURE 3

made any easier by the frequency and magnitude of aftershocks some of which were so bad that it was necessary to withdraw the inspection groups because of the danger of falling objects.

From week two to week twelve the structure was as shown in Figure 4 which was set up to give emphasis to the procurement, design and build aspects of the reconstruction work.

By the time week twelve came around there was a significant part of the mill back in normal operation and the structure was reformed (Figure 5) to cover the normal management practices and to treat the outstanding major earthquake repairs as special projects, each under the control of a Project Manager with a suitable support infrastructure. 


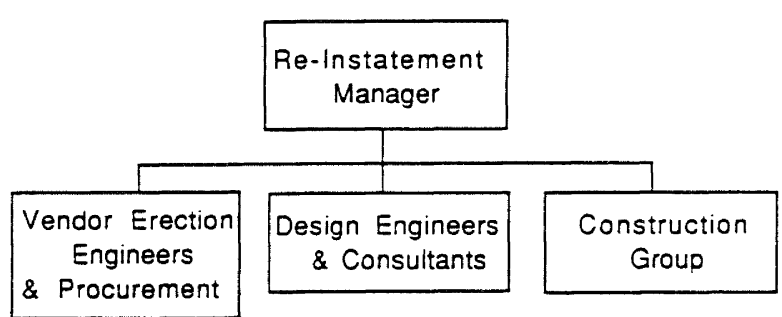

FIGURE 4

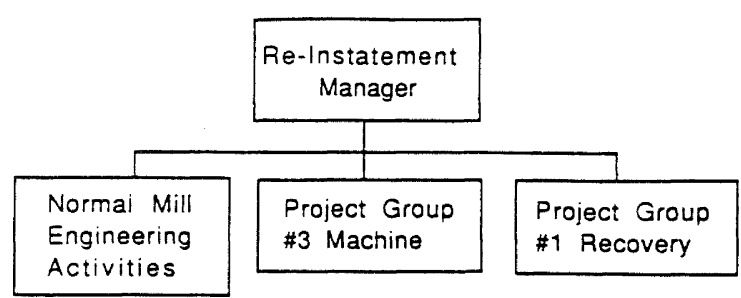

FIGURE 5

\section{SOME EARLY PLANS}

When considering a fourth newsprint machine in the early 1980's we had concerns over the exposure of such a capital intensive site in an earthquake/volcano prone country. A survey was undertaken by one of our consultants [3], to consider various disasters and compare these with other geographical areas, in both the central North Island and overseas. This study was useful, if perhaps a little frightening and of course deep down we didn't really believe that any of the potential hazards would happen, at least, not in our lifetime. The review was largely academic, the incidents were based on frequency simulations and shock wave attenuations and the like which were highly theoretical, even if well founded but which had never really been tested. The conclusions were that New Zealand exposure is low compared with some other countries and Kawerau had equal or lower risks than some other areas within New Zealand.

No effective plan can be formulated without dedication and commitment. The major difficulty in conceiving a disaster plan is the acceptance of the fact that there is a probability of experiencing a significant disaster.

Our consultants report [3] highlighted the following seemingly obvious events.

Seismic Events, which may involve severe ground shaking leading to liquefaction of some soils, collapse of soil structures under buildings or plant foundations, land slips, fissures in weak ground affecting plant, buildings or access, collapse of bridges or bridge approaches, failure of natural restraining features, tsunamis, failure of structures, loss of essential services, outbreak of fire etc.,

Volcanic Events which could include eruptions leading to falls of dust, ash, scoria, pumice, pyroclastic flows, mud flows, lava flows and hydrothermal explosions. Resulting potential damage could arise from the effects of impact, thrust, burial, turbulent gas and fire.

It may be of interest to note that in 1985 we discovered some serious corrosion in beam to column connections on No 1 Chemical Recovery Unit which were partly exposed to both the elements and the deposition of saltcake in places which were difficult to inspect. An immediate design review was undertaken, a crash remedial programme was implemented and this structure was restored prior to the earthquake.

\section{PLANNING FOR DISASTER}

From the foregoing experience it can readily be seen that there are some issues which can be determined before being faced with a disaster, thus easing the impact of decision making when confronted by such circumstances. Some of these are:-

Consider a disaster situation. From the qualities of the people available, you can decide who could head up the re-instatement programme.

Consider the application of the insurance policy for repair or replacement and the impact of consequential loss. Review the main features of the insurance policies which would have to be addressed in any claim.

The history of the plant may make the choice of design consultants an easy matter but if not you may wish to investigate consultants with the necessary attributes for a fast response.

An after hours list of both domestic and overseas people can be established and kept updated so that vendors or other specialists can be contacted at any time of the day or night.

A programme of regular emergency evacuations can be carried out.

Review whether or not you have a building suitable for a control centre, with communications and medical facilities, which may withstand earthquakes. Perhaps you need one.

Educate key people in the significant features of insurance policies and the requirements for handling major claims.

If your organisation is not Engineer intensive, address how to appoint engineers of your choice acceptable to the insurers. Know where to get expert assistance in all disciplines involved in your business. 
Train as any people as possible in dealing with emergencies and follow up with more training and practise. It may be later than you think. Plan for the most effective use of production labour not required for clean up or repair. There may be a variety of skills in your workforce not utilised in the normal business.

Carry out some level of risk assessment of your plant. A design review is not cheap or necessarily easy to perform because there may be a wide range of design codes involved if the plant is old enough to have had different criteria applied. Such reviews necessarily involve a wide range of assumptions but whether the correct ones are chosen or not there will be sufficient information to alert the owner to some likely effects of a design level disaster on his plant.

Conduct regular and frequent inspections of structures to ensure they are free from defects which may be hidden on a day to day basis.

Ensure the office layouts are such as to make egress easy when filing cabinets and bookshelves respond to violent shaking. Where possible secure these items.

If your company incorporates major plant used on a world wide basis ask the vendors if that equipment has been exposed to a major disaster. Now is a good time to do this. Vendors may not be readily forthcoming in an actual disaster situation.

Secure all stores racking and make sure they will withstand violent shaking.

Examine your situation now for emergency water supply in the event of the loss of existing underground systems.

Earthquakes that cause damage are violent indescribable experiences which are best read about. If you have to experience a major event, and you may, then try to be prepared.

Take the view that it can happen to you tomorrow.

\section{REFERENCES}

1. Sir Michael Fowler, "The seismic upgrading of buildings - its effect upon Wellington City", New Zealand Engineering November 1, 1983.

2. W.C. Hodge and M. Macfarlane, "Effect of the Edgecumbe Earthquake on Mechanical and Process Equipment at the Tasman Mill", Bulletin of the New Zealand Society for Earthquake Engineering, Vol. 21 , No 3, September 1988.

3. Beca Carter Hollings \& Ferner Limited, "A Study of Risks from Major Natural Events", (A Tasman Internal Report), 1980 . 